\title{
HOW DOES AN INDUSTRY CONTROL A DECISION SUPPORT SYSTEM FOR A LONG TIME?
}

\author{
Mrudul Y. Jani ${ }^{1}$, Urmila Chaudhari ${ }^{2}$ And Biswajit Sarkar ${ }^{3,4 *}$
}

\begin{abstract}
The inventory system has been affected by many characteristics, among which deterioration of a food product is a critical issue. Chilled foods deteriorate during storage time, and their quality reduces over time. Indian Spiced Pulled Pork Sandwiches are very observable customer goods in India that are, in fact, unpreserved. If chilled foods' original value reduces over time, consumers are not much likely to buy them. The retail price of chilled food maintained is strictly dependent on its quality. From the vendor's approach, measuring quality and leftover value should be a severe commercial issue. The model aims to study deterioration together with the quality prediction of Indian Spiced Pulled Pork Sandwiches. This model measures food quality and leftover value. Deterioration rate is considered as a function of two-parameter Weibull distribution, suitable for bacterial inactivation, microbial growth, enzymes, nutrients, and pigments dreadful environments under a non-isothermal atmosphere. The dynamic structure of demand has its importance in business. The price-storage time of product-dependent demand rate is debated in this model as demand rarely remains constant. The objective is to maximize the vendor's total profit concerning storage time and the product's selling price. A numerical example supports the model. Sensitivity analysis is carried out to derive insights for decision-makers. The graphical result, in three dimensions, is exhibited with a supervisory decision.
\end{abstract}

Mathematics Subject Classification. 90B05.

Received June 20, 2020. Accepted April 17, 2021.

\section{INTRODUCTION}

Preservation of the quality and inventories of chilled foods are significant issues in food industries. Mainly, as the chain's variation temperature is dynamic, temperature observing during the selling is a common observation and critical effort. Conversely, Grievink et al. [7] recognized that seasonality in material fabrication requires airconditioned shipping, and storage is challenging. Although increasing numbers of researchers have deliberated temperature observation in food industries, very little attention has been specified, especially to ready-to-eat

Keywords. Decision support system, quality of food, performance of foods, Gompertz function, Pseudomonas spices.

1 Department of Applied Sciences and Humanities, Parul Institute of Engineering and Technology, Parul University, Vadodara 391760, Gujarat, India.

2 Government Polytechnic Dahod, Dahod 389151, Gujarat, India.

3 Department of Industrial Engineering, Yonsei University, 50 Yonsei-ro, Sinchon-dong, Seodaemun-gu, Seoul 03722, South Korea.

* Corresponding author: bsbiswajitsarkar@gmail.com

4 Department of Computer Science and Engineering, Saveetha School of Engineering, Saveetha Institute of Medical and Technical

Sciences, Saveetha University, 162, Poonamallee High Road, Velappanchavadi, Chennai, Tamilnadu 600077, India

(C) The authors. Published by EDP Sciences, ROADEF, SMAI 2021

This is an Open Access article distributed under the terms of the Creative Commons Attribution License (https://creativecommons.org/licenses/by/4.0), which permits unrestricted use, distribution, and reproduction in any medium, provided the original work is properly cited. 
chilled food. Chilled food becomes a part of real-life these days [5]. Herbon et al. [8] directed that chilled food's quality maintenance is an important task to boost the food industries' business. Furthermore, the consequences of deterioration, demand, and price of chilled food products cannot be ignored in inventory organizations. Thus, the main aim is to develop a model to optimize the storage time and storage temperature of ready-to-eat chilled food for maximum profit. The study of the literature to recognize presently ignored research aspects is as follows.

\subsection{Literature review on quadratic demand}

Most of the articles in the past were discussed for constant demand. Inversely, demand rarely remains constant for the infinite horizon. Shah et al. [27] formulated an inventory model with permissible delay in payment and buyback policy for price-sensitive quadratic demand. Shah et al. [29] offered the model on the impact of future price increase on ordering policies under the effect of quadratic demand. Shah and Jani [26] studied an economic order quantity (EOQ) model under order-size-dependent trade credit for price-sensitive quadratic demand. Mukherjee and Mahata [15] discussed an optimal replenishment and credit policy in an inventory model under two-levels of trade credit policy when demand depends on both time and credit period involving default risk. Dey et al. [4] determined an integrated inventory model with price-sensitive demand. Shaikh et al. [32] invented a two-warehouse inventory model with interval-valued inventory costs and stock-dependent demand under inflationary conditions. In recent times, Sarkar et al. [21] offered an optimal replenishment decision for retailers with variable demand under a trade-credit policy. Shah et al. [30] discussed integrating credit and replenishment policies under quadratic demand in a three-echelon supply chain. Khan et al. [12] investigated the effect of advance payment with the discount facility on supply decisions whose demand is both price and stock-dependent.

\subsection{Literature review on deterioration}

Deterioration of items like volatile liquids, fruits, vegetables, beverages, medicine, blood in the form of natural decay or damage, on-going physical decay over time, or obsolescence is a natural occurrence. It has a substantial effect on the player's inventory policies. Taleizadeh and Nematollahi [34] evaluated an inventory control problem for perishable items with financial deliberations and back-ordering. Rabbani et al. [18] founded the model for non-instantaneous stock-dependent deterioration of the supply chain. Shah et al. [28] discussed an optimal downstream permissible delay in payment and cycle time for deteriorating inventory in a supply chain. Shah and Chaudhari [24] studied optimal strategies for three players with fixed lifetime and two-level credit limit for time and credit-dependent demand. Furthermore, Zhang et al. [38] established an integrated model for perishable items with a cooperative investment contract and revenue sharing. Sarkar et al. [20] estimated flexible setup costs and deterioration of products in a supply chain model. Shah and Jani [25] determined an inventory model for deteriorating fixed lifetime with quadratic demand and up and downstream credit limits. Rabbani et al. [19] studied optimal joint inventory, dynamic pricing, and advertisement policies for non-instantaneous deteriorating items. Mahapatra et al. [14] developed a fuzzy EOQ model of deteriorating items with promotional effort and learning fuzziness with a finite time horizon. Iqbal and Sarkar [9] established the recycling of lifetimedependent deteriorated items through different supply chains. Jemai et al. [11] offered a sustainable approach to environmental effect for a complex green supply chain management to control waste. Saxena et al. [23] investigated a selection of remanufacturing/production cycles with an alternative market perspective on waste management. Mukhopadyay et al. [16] debated pricing and lot-sizing dependent model with a time relative and two-parameter Weibull distribution deterioration rate. Shaikh et al. [31] considered an inventory model for a three-parameter Weibull distribution. Recently, Sarkar et al. [22] studied the combined effects of carbon emission and production quality improvement for fixed lifetime products in sustainable supply chain management.

\subsection{Literature review on chilled food}

Food items are very communal customer goods in day-to-day life. Several families have switched family meals with chilled food, as chilled food is more suitable than family meals. Fang et al. [5] studied the Microbiological 
TABLE 1. Contributions of different authors.

\begin{tabular}{|c|c|c|c|}
\hline Authors & Deterioration & Demand & Predictive quality model \\
\hline Qin et al. [17] & $\begin{array}{l}\text { Two-parameter } \\
\text { Weibull distribution }\end{array}$ & $\begin{array}{l}\text { Stock quality and selling } \\
\text { price dependent }\end{array}$ & NA \\
\hline Shah and Chaudhari [24] & Fixed lifetime & Time and credit dependent & NA \\
\hline Yang and Tseng [37] & $\begin{array}{l}\text { Temperature- } \\
\text { dependent }\end{array}$ & Price dependent & Gompertz model \\
\hline Shah et al. [29] & Constant & Quadratic & NA \\
\hline Shaikh et al. [31] & $\begin{array}{l}\text { Three-parameter } \\
\text { Weibull distribution }\end{array}$ & $\begin{array}{l}\text { Frequency of advertisement } \\
\text { and selling price dependent }\end{array}$ & NA \\
\hline Sarkar et al. [21] & Time-varying & $\begin{array}{l}\text { Selling price-credit period } \\
\text { dependent }\end{array}$ & NA \\
\hline Sarkar et al. [22] & Time-varying & Constant & NA \\
\hline This paper & $\begin{array}{l}\text { Two-parameter } \\
\text { Weibull distribution }\end{array}$ & $\begin{array}{l}\text { Price and storage } \\
\text { time-dependent quadratic } \\
\text { demand }\end{array}$ & Gompertz model \\
\hline
\end{tabular}

Notes. NA indicates not available.

quality of $18^{\circ} \mathrm{C}$ ready-to-eat food items sold in Taiwan. Chilled food has been integrated into numerous inventory models together with deterioration rate [10,37]. Chilled food is, therefore, the most suitable perishable item for inclusion in the inventory policy. Herbon et al. [8] applied time-temperature indicators (TTI) to observe the trajectory of the quality of deteriorated items. They appealed that the retail price of deteriorated items and their leftover value had much to do with their quality, affecting the vendor to pay attention to maintain quality. It is therefore of interest to be able to quantify the quality of food and its remaining value. Qin et al. [17] expressed the selling price and lot-sizing dependent model for food items where the value and quantity deteriorated at the same time. They specified that temperature plays a keen role in the deterioration rate. Thus, the deterioration rate should fluctuate with temperature when taking chilled food as the study object.

\subsection{Literature review on predictive quality model}

Noticing the growth of microorganisms is an extremely reliable methodology to define food quality and food safety. If microorganisms' abundance goes beyond the standard value, the food can be demonstrated as uneatable [1]. Gibson et al. [6] analyzed the Gompertz model to construct an analytical model of microorganisms. Whiting and Buchanan [36] specified that the Gompertz model thoroughly fitted the growth curve of microorganisms. Linton et al. [13] recognized the modified Gompertz model's nonlinear existence curve for Listeria monocytogenes. Chowdhury et al. [3] projected the growth of Pediococcus acidilactici by applying the Gompertz model and the logistic model. Moreover, they linked the predictive ability of these two prototypes. They observed the Gompertz model as a proper model for calculating food quality. Wang et al. [35] presented an application of a predictive growth model of Pseudomonas spp. for estimating the shelf life of fresh Agaricus bisporus. Recently, Stavropoulou and Bezirtzoglou [33] studied the predictive modeling of microbial behavior in food (Table 1).

With the comparison of existing literature work, a predictive quality Gompertz model of Indian Spiced Pulled Pork Sandwiches (chilled food) is established in this article under price and storage time-dependent quadratic demand. This predictive model defines the growth level of Pseudomonas species with storage time and storage temperature. Moreover, obtaining specific data from some industries and laboratories is a very crucial task. Furthermore, statistical methods to evaluate deterioration rate are again costly job as a researcher requires some statistics based software for data analysis. Instead of considering traditional data analysis techniques for measuring deterioration rate, a function of two-parameter Weibull distribution is used as a deterioration rate, 
which is more appropriate to describe microbial inactivation, microbial growth, and pigments, nutrients, and enzymes dreadful conditions under non-isothermal environment [17].

The remaining part of the paper is organized as follows. Section 2 is the notation and assumptions used for the development of the proposed problem. Derivation of the mathematical model is in Section 3. The numerical study is described in Section 4. The sensitivity analysis of critical parameters is carried out in Section 5. Finally, Section 6 includes the conclusions of the study and its future scopes.

\section{Notation AND ASSUMPtions}

The proposed inventory problem is based on the following notation and assumptions.

\subsection{Notation}

\begin{tabular}{|c|c|}
\hline$A$ & ordering cost per order $(\$ /$ order $)$ \\
\hline$C$ & purchasing cost per unit (\$/unit) \\
\hline$h$ & holding cost per unit item per unit time ( $\$ /$ unit/unit time) \\
\hline$p$ & selling price per unit (\$/unit) (decision variable), $p>C$ \\
\hline$U$ & the storage temperature of an item $\left({ }^{\circ} \mathrm{C}\right)$ \\
\hline$K$ & time at which maximum growth rate of Pseudomonas species occurs (hours) \\
\hline$T$ & storage time (hours) (decision variable) \\
\hline$Q$ & inventory level at the time $t=0$ (units) \\
\hline$N_{0}$ & an initial count of bacteria in food (log $\mathrm{CFU} / \mathrm{g})$ \\
\hline$G$ & bacterial growth count in food (log CFU/g) \\
\hline$N(t)$ & end bacterial count of food at a time $t(\log \mathrm{CFU} / \mathrm{g}), 0 \leq t \leq T$ \\
\hline$\chi(t)$ & remaining ratio of the value after deterioration per unit item \\
\hline$I(t)$ & inventory level at a time $t$ (units), $0 \leq t \leq T$ \\
\hline$\pi(p, T)$ & otal profit per cycle $(\$ /$ cycle $)$ \\
\hline
\end{tabular}

\subsection{Assumptions}

(1) The inventory system deals with a single item. Indian spiced pulled pork sandwich (ready-to-eat chilled food) is considered as a research product in this model.

(2) Pseudomonas species are the detected microorganisms on Indian spiced pulled pork sandwiches. Due to the growth of these species, the product deteriorates. The time at which the maximum growth rate of Pseudomonas species occurs in Indian spiced pulled pork sandwiches is the function of temperature $U$, i.e. $K=96.332 e^{-0.127 U}$. After this time limit, the product will become uneatable. Nearly all the meat products will be uneatable if Pseudomonas species exceed the limit $7 \log \mathrm{CFU} / \mathrm{g}$. That means the product entirely deteriorates.

(3) Set $\chi(t)=\frac{7-N(t)}{7} ; 0<\chi(t)<1$, then the value of $\chi(t)$ will reduce if $N(t)$ increases.

(4) The demand rate, $R(p, t)=a p^{-\eta}\left(1+b t-c t^{2}\right)$ is a function of storage time $t$ and selling price $p$; where $a>0$ is scaling parameter, $0 \leq b<1$ denotes the linear rate of change of demand with respect to time, $0 \leq c<1$ denotes the quadratic rate of change of demand, and $\eta>1$ is marked up for selling price, (Shah and Jani [26]). Demand is depending upon selling price and storage time.

(5) The instantaneous deterioration rate of Indian spiced pulled pork sandwiches is a function of temperature, i.e. $\theta(U)=\alpha \beta U^{\beta-1} ; \alpha>0, \beta>1$, which is a two-parameter Weibull distribution, Mukhopadyay et al. [16]. Weibull distribution is more suitable for microbial growth and bacterial inactivation under a non-isothermal atmosphere. The planning horizon is infinite, which will facilitate a long-time agreement. Lead time is considered negligible. Shortages are not allowed.

\section{Mathematical MOdel}

In this model, one cycle is analyzed. The cycle starts with the selling of Indian spiced pulled pork sandwiches to the customers in the given time interval $[0, T]$. In this time interval, the rate of change of inventory is 
negatively proportional to the selling price-storage time-dependent demand rate and temperature-dependent deterioration rate that is regulated as follows:

$$
\frac{\mathrm{d} I(t)}{\mathrm{d} t}=-R(p, t)-\theta(U) I(t), \quad 0 \leq t \leq T,
$$

with the boundary condition $I(T)=0$. (It is assumed that at a time $t=T$, an inventory level is zero.)

The level of stock of sandwiches at any time $t$ is given by

$$
I(t)=E_{1}\left(E_{2}+E_{3} t+E_{4} t^{2}-e^{\theta(U)(T-t)} E_{5}\right), \quad 0 \leq t \leq T
$$

where $E_{1}, E_{2}, E_{3}, E_{4}$, and $E_{5}$ are described in Appendix A.

When storage time is zero, the stock level of sandwiches by considering $t=0$ in equation (3.1) is represented by $Q=E_{1}\left(E_{2}-e^{\theta(U) T} E_{5}\right)$.

With the help of a derivation of the total profit, the mathematical expressions of ordering cost, holding cost, and purchasing cost are calculated as follows:

- Ordering cost.

This cost is associated with dispensation and chasing of the procurement of order, quality inspection, and transportation. This cost is considered as a fixed cost in this study. Ordering cost is described by OC $=\frac{A}{T}$.

- Holding cost.

This cost is associated with holding or carrying the merchandise in stock. Rent, taxes, the interest of invested money, depreciation, and insurance are included in holding costs. Holding cost is defined by $\mathrm{HC}=$ $\frac{h}{T}\left(\int_{0}^{T} I(t) \mathrm{d} t\right)$.

- Purchasing cost.

It is the cost of purchasing a unit of item. It is considered as constant. It is defined by $\mathrm{PC}=\frac{C Q}{T}$.

In connection with the product's sales is concerned, the Gompertz model is applied as the primary model to define Pseudomonas species' growth with time Gibson et al. [6]. Gompertz model is defined by

$$
N(t)=N_{0}+G e^{-e^{-\theta(U)(t-K)}}, \quad \chi(t)=\frac{7-N(t)}{7} ; \quad 0<\chi(t)<1 .
$$

- Sales revenue.

The amount generated by the selling of every unit is referred to as sales revenue, and it is defined by $\mathrm{SR}=\psi(p, T)$, where $\psi(p, T)=\frac{p}{T}\left(\int_{0}^{T} R(p, t) \chi(t) \mathrm{d} t\right)$.

As a result, the total profit per cycle is

$$
\pi(p, T)=\mathrm{SR}-\mathrm{OC}-\mathrm{HC}-\mathrm{PC} .
$$

\subsection{Solution methodology}

The total profit function $\pi(p, T)$ is a continuous function of the selling price $p$ and the storage time $T$. The first order derivative of the profit function with respect to $p$ is as follows:

If $\frac{\partial \pi(p, T)}{\partial p}=0$, then $p$ is called optimal selling price, and it is denoted by $p^{*}$.

It can be evaluated as

$$
\frac{\partial \pi(p, T)}{\partial p}=\frac{\partial \psi(p, T)}{\partial p}-\frac{a p^{-\eta-1} \eta}{6 \theta T}\left(\begin{array}{l}
2 E_{4} T^{3} h \theta+3 E_{3} T^{2} h \theta-6 C E_{5} e^{\theta T} \theta \\
+6 E_{2} h T \theta+6 C E_{2} \theta-6 E_{5} e^{\theta T} h+6 E_{5} h
\end{array}\right) .
$$


By taking $\frac{\partial \pi(p, T)}{\partial p}=0$, the optimal selling price can be obtained as

$$
p^{*}=\frac{7 \eta\left(C\left(E_{2}-e^{\theta(U) T} E_{5}\right)+h E_{7}\right)}{E_{6}(1-\eta)} .
$$

If $\frac{\partial \pi(p, T)}{\partial T}=0$, then $T$ is called optimal storage time and it is denoted by $T^{*}$.

This can be evaluated as follows:

$$
\frac{\partial \pi(p, T)}{\partial T}=\frac{\partial \psi(p, T)}{\partial T}-\frac{1}{6 \theta T^{2}}\left(\begin{array}{l}
6 C E_{1} E_{4} e^{\theta T} T^{3} \theta^{2}+6 C E_{1} E_{3} e^{\theta T} T^{2} \theta^{2} \\
+6 E_{1} E_{4} e^{\theta T} T^{3} \theta h+6 C E_{1} E_{2} e^{\theta T} T \theta^{2} \\
+6 C E_{1} E_{4} e^{\theta T} T^{2} \theta+6 E_{1} E_{3} e^{\theta T} T^{2} \theta h \\
-4 E_{1} E_{4} T^{3} \theta h+6 E_{1} E_{2} e^{\theta T} T h \theta \\
-3 E_{1} E_{3} T^{2} \theta h+6 E_{1} E_{4} e^{\theta T} T^{2} h \\
-6 C E_{1} E_{2} e^{\theta T} \theta-6 E_{1} E_{4} T^{2} h \\
+6 C E_{1} E_{2} \theta-6 E_{1} E_{2} e^{\theta T} h+6 E_{1} E_{2} h \\
+6 A \theta
\end{array}\right)
$$

By taking $\frac{\partial \pi(p, T)}{\partial T}=0$, the optimal storage time can be obtained as follows,

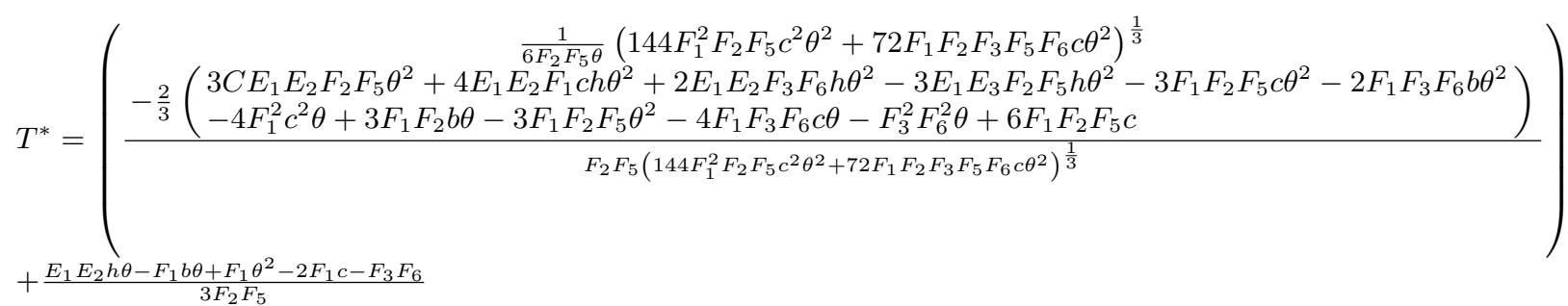

The total profit function's concavity is obtained by the Hessian matrix (Appendix B).

$$
H(p, T)=\left[\begin{array}{ll}
\frac{\partial^{2} \pi(p, T)}{\partial T^{2}} & \frac{\partial^{2} \pi(p, T)}{\partial p \partial T} \\
\frac{\partial^{2} \pi(p, T)}{\partial T \partial p} & \frac{\partial^{2} \pi(p, T)}{\partial p^{2}}
\end{array}\right] .
$$

Now, according to Cárdenas-Barrón and Sana [2], if the Hessian matrix's eigenvalues at the solution $(p, T)$ are all negative, then the total profit function $\pi(p, T)$ is maximum at that solution. So, adopting this concept to check the optimality, Eigenvalues $\left(\lambda_{1}\right.$ and $\left.\lambda_{2}\right)$ of the above Hessian matrix are evaluated.

An endorsement of the proposed model will be established using the following numerical example.

\section{Numerical EXAMPLE}

By taking data some important parameters from Yang and Tseng [37] as, $a=10,000$ units, $b=2 \%, c=8 \%$, $\eta=1.2, C=\$ 10$ per unit, $A=\$ 100$ per order, $h=1$ per unit time, $N_{0}=3.13 \log \mathrm{CFU} / \mathrm{g}, G=6.87 \log \mathrm{CFU} / \mathrm{g}$, $\alpha=0.1, \beta=1.1$ and by considering different values of $U$ and $T$, the value of $p^{*}$ and $\pi^{*}(p, T)$ can be exhibited as in Table 2 .

\subsection{Sensitivity analysis}

Table 2 shows that the selling price of a product increases with the rise of storage time and storage temperature to invigorate the total profit. Moreover, one can observe the effect of storage temperature and storage time on the optimal profit. Table 2 is analyzed using Maple 18 software that when the storage temperature is $1{ }^{\circ} \mathrm{C}$ the optimal values of total profit, selling price, and storage time are $\$ 1654.60, \$ 114.72$, and 1 hour. 
TABLE 2. Optimal solutions.

\begin{tabular}{llllllll}
\hline \hline \multirow{2}{*}{$U\left({ }^{\circ} \mathrm{C}\right)$} & Decision variables & \multicolumn{6}{c}{$T$ (hour) } \\
\cline { 2 - 8 } & Total profit & 0.25 & 0.50 & 1.00 & 2.00 & 3.00 & 4.00 \\
\hline \multirow{2}{*}{$1{ }^{\circ} \mathrm{C}$} & $p^{*}(\$ /$ unit $)$ & 110.05 & 111.60 & $\mathbf{1 1 4 . 7 2}$ & 120.82 & 125.76 & 126.60 \\
& $\pi^{*}(p, T)(\$ /$ cycle $)$ & $1,400.73$ & $1,591.23$ & $\mathbf{1 , 6 5 4 . 6 0}$ & $1,562.89$ & $1,350.63$ & $1,048.04$ \\
\hline $6{ }^{\circ} \mathrm{C}$ & $p^{*}(\$ /$ unit $)$ & 110.54 & 112.40 & 116.19 & 123.66 & 129.80 & 130.85 \\
& $\pi^{*}(p, T)(\$ /$ cycle $)$ & $1,396.01$ & $1,585.50$ & $1,646.96$ & $1,552.29$ & $1,339.10$ & $1,038.79$ \\
\hline $11{ }^{\circ} \mathrm{C}$ & $p^{*}(\$ /$ unit $)$ & 113.15 & 115.22 & 119.44 & 127.85 & 134.80 & 135.99 \\
& $\pi^{*}(p, T)(\$ /$ cycle $)$ & $1,348.32$ & $1,536.89$ & $1,597.02$ & $1,502.20$ & $1,293.20$ & $1,002.82$ \\
\hline $16{ }^{\circ} \mathrm{C}$ & $p^{*}(\$ /$ unit $)$ & 123.69 & 126.26 & 131.55 & 142.20 & 151.16 & 152.71 \\
& $\pi^{*}(p, T)(\$ /$ cycle $)$ & $1,172.06$ & $1,358.27$ & $1,415.49$ & $1,323.43$ & $1,131.42$ & 876.27 \\
\hline $21{ }^{\circ} \mathrm{C}$ & $p^{*}(\$ /$ unit $)$ & 146.53 & 150.25 & 157.99 & 174.03 & 187.99 & 190.45 \\
& $\pi^{*}(p, T)(\$ /$ cycle $)$ & 883.50 & $1,066.06$ & $1,118.94$ & $1,032.12$ & 868.28 & 670.50 \\
\hline
\end{tabular}

Notes. Bold values represent optimum values.

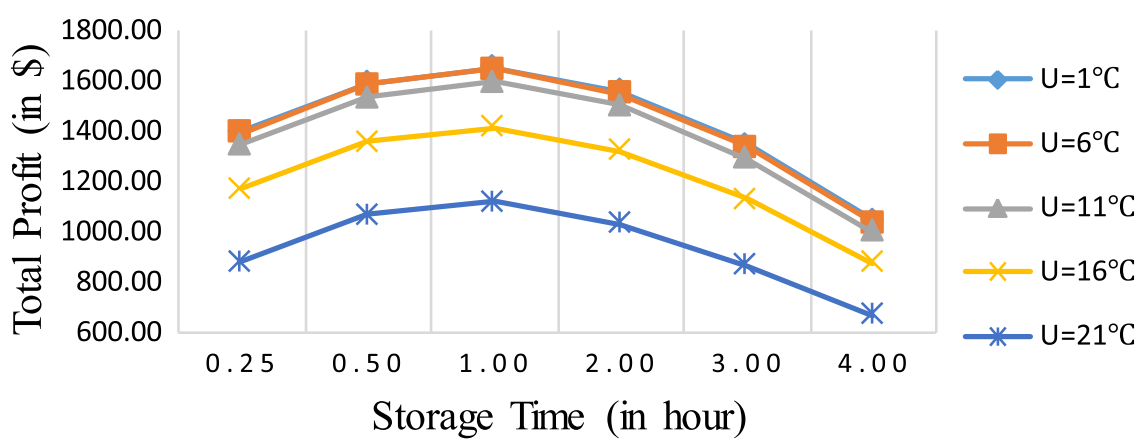

FIgURE 1. Optimal total profit under different storage temperature and storage time.

The following Figure 1 shows an effect of the quadratic demand of storage time on optimal profit. It is shown that initially, the demand for Indian spiced pulled pork sandwiches increases for the storage period from 0.25 hours to 1 hour. At a storage time of 1 hour, the demand for the product is maximum; however, when the storage time exceeds the limit of 1 hour, the demand starts to decrease.

Substituting optimal values of selling price and storage time in the Hessian matrix $H(p, T)$,

$$
H(p, T)=\left[\begin{array}{ll}
-293.33460 & 0.2003346 \\
0.2003346 & -0.31997503
\end{array}\right] .
$$

Here, both the eigenvalues $\lambda_{1}=-0.318$ and $\lambda_{2}=-293.334$ are negative. So, the total profit function $\pi(p, T)$ is maximum.

The maximization of the total profit is shown graphically for the obtained results in Figure 2 .

For different inventory parameters, the sensitivity analysis of numerical example is carried out in Table 3 by changing one variable at a time as $-20 \%,-10 \%, 10 \%$, and $20 \%$.

From Table 3, it can be seen that scale demand has a substantial favorable impact on total profit. It is pronounced that if the product's scaling parameter of demand is more, then the total profit is more. Moreover, it is observed that the initial count of bacteria in food and purchase cost per unit have enormous positive impact on selling price and a negative impact on total profit. This behavior is when the product's selling price starts to increase, and then the total profit starts to decrease. Furthermore, when the mark-up of selling price decreases, selling price decreases rapidly, and because of that the total profit decreases hugely. 


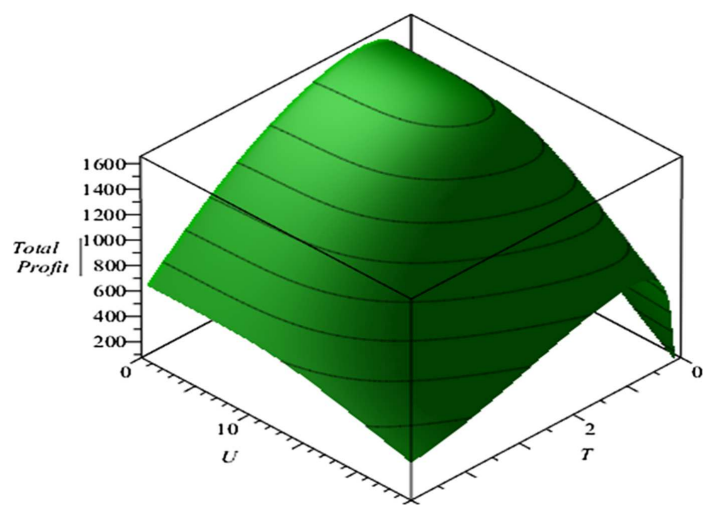

Figure 2. Concavity of total profit $\pi(p, T)$ versus storage temperature $U$ and storage time $T$.

TABLE 3. Sensitivity analysis.

\begin{tabular}{lllllll}
\hline \hline \multirow{2}{*}{ Inventory parameters } & \multirow{2}{*}{ Decision variables (in $\$)$} & \multicolumn{5}{c}{ Changes } \\
\cline { 3 - 7 } & & $-20 \%$ & $-10 \%$ & $0 \%$ & $10 \%$ & $20 \%$ \\
\hline$a$ & $p^{*}$ & 114.72 & 114.72 & 114.72 & 114.72 & 114.72 \\
& $\pi^{*}(p, T)$ & $1,303.68$ & $1,479.14$ & $1,654.60$ & $1,830.06$ & $2,005.52$ \\
\hline$N_{0}$ & $p^{*}$ & 98.75 & 106.13 & 114.72 & 124.81 & 136.86 \\
& $\pi^{*}(p, T)$ & $2,000.49$ & $1,826.25$ & $1,654.60$ & $1,485.71$ & $1,319.76$ \\
\hline$C$ & $p^{*}$ & 91.79 & 103.25 & 114.72 & 126.19 & 137.65 \\
& $\pi^{*}(p, T)$ & $1,734.64$ & $1,691.95$ & $1,654.60$ & $1,621.49$ & $1,591.80$ \\
\hline$\eta$ & $p^{*}$ & - & 258.12 & 114.72 & 78.87 & 62.57 \\
& $\pi^{*}(p, T)$ & - & $3,127.88$ & $1,654.60$ & 917.89 & 511.66 \\
\hline
\end{tabular}

\section{MANAGERIAL INSIGHTS}

This article proposes food items whose quality reduces the most over time. Tracking the quality of deteriorating items such as chemicals, food items, or medicines is necessary to notice their remaining value. The industry manager can concentrate on the reduction of the deterioration by controlling the temperature or other factors. The cycle length is the most sensitive issue for the managers as the increasing value of these products' holding may increase deterioration. The industry manager can think over the storage place with more cooling such that those foods can be stored for a long time without deterioration. Concentrating on excessive cold-storage may increase the selling price of the product. Thus, the optimum selling price is another most sensitive part of the management sector.

\section{Conclusions}

This article considered the deteriorating inventory model as deterioration is a critical issue of inventory policy. Chilled foods deteriorated during the storage time, and foods' quality reduce or even be lost. It was remarkable to identify how to quantize quality and remaining value. Therefore, the predictive quality model was applied to define quality and leftover value. This model proposed that Indian spiced pulled pork sandwiches as a research item. The Gompertz model was used, which closely fits the growth curve of microorganisms on food products to control the quality of Indian spiced pulled pork sandwiches once deterioration has started. As a final point, an example was demonstrated to explain the proposed model with different storage times and storage 
temperatures. It could support to measure the whole system profit under different storage times and storage temperature. It was found that the profit can be maximized if the deterioration can be appropriately controlled. The optimum selling price gave a significant profit under the optimum controlling of the temperature for reducing the deterioration rate. The model discovered that higher storage temperatures and storage times beyond the limit reduce profit and shorten the replenishment cycle. It is expected that this work will inspire future works in this area. Further study will be expanded on more real-world complications. In the entire lifespan, storage temperature will be affected by an electrically powered system, refrigeration equipment, refrigeration method, and similar factors. In other words, temperature variability during storage is standard. Time-dependent demand plays a keen role in the vendor's profit. One can apply the fuzzy theory to pretend temperature instability. This model can be further extended by considering the temperature-dependent deterioration with the preservation technology, where the demand must be selling price-dependent. Though the advanced payment is an effective strategy for profit, the advanced profit and partial payment combination may be better than only considering advanced payment. That would be an excellent idea to extend this model again.

\section{Appendix A.}

The values of $E$ 's are as follows:

$$
\begin{aligned}
& E_{1}=-a p^{-\eta} \\
& E_{2}=\frac{1}{\theta(U)}-\frac{b}{\theta^{2}(U)}-\frac{2 c}{\theta^{3}(U)} ; \\
& E_{3}=\frac{b}{\theta(U)}+\frac{2 c}{\theta^{2}(U)} ; \\
& E_{4}=\frac{-c}{\theta(U)} ; \\
& E_{5}=E_{2}+E_{3} T+E_{4} T^{2} \\
& E_{6}=\left(\begin{array}{l}
\left(7-N_{0}\right)\left(T+\frac{b T^{2}}{2}-\frac{c T^{3}}{3}\right) \\
+\frac{e^{\theta(U)(T-K)-1} G}{\theta(U)}\left(-1-b T+\frac{b}{\theta(U)}+c\left(T^{2}-\frac{2 T}{\theta(U)}+\frac{2}{\theta^{2}(U)}\right)\right)+E_{8}
\end{array}\right) ; \\
& E_{7}=E_{2} T+E_{3} \frac{T^{2}}{2}+E_{4} \frac{T^{3}}{3}+\frac{E_{5}}{\theta(U)}\left(1-e^{\theta(U) T}\right) ; \\
& E_{8}=\frac{e^{-\theta(U) K-1} G}{\theta(U)}\left(1-\frac{b}{\theta(U)}-\frac{2 c}{\theta^{2}(U)}\right) .
\end{aligned}
$$

The Values of $F$ are as follows:

$$
\begin{aligned}
& F_{1}=\frac{p a G e^{-1} T^{2}}{7 p^{\eta} e^{\theta M} \theta e^{\theta T}} \\
& F_{2}=\frac{2 p a c}{3 T p^{\eta}} \\
& F_{3}=\frac{p a b}{2 p^{\eta}} \\
& F_{4}=\frac{p a T^{2} G e^{-1}}{p^{\eta} \theta e^{\theta M}}
\end{aligned}
$$




$$
\begin{aligned}
& F_{5}=-F_{6}=\left(\frac{A_{0}}{7}-1\right) \\
& F_{6}=\left(1-\frac{A_{0}}{7}\right) \\
& F_{7}=\left(-1+\frac{2 c}{\theta^{2}}+\frac{b}{\theta}\right)
\end{aligned}
$$

\section{Appendix B. Hessian matrix}

To prove the concavity condition of total profit $\pi(p, T)$, we evaluate the Hessian matrix as follows:

$$
\begin{aligned}
& \frac{\partial \pi(p, T)}{\partial p}=\frac{\partial \psi(p, T)}{\partial p}-\frac{a p^{-\eta-1} \eta}{6 \theta T}\left(\begin{array}{l}
2 E_{4} T^{3} h \theta+3 E_{3} T^{2} h \theta-6 C E_{5} e^{\theta T} \theta \\
+6 E_{2} h T \theta+6 C E_{2} \theta-6 E_{5} e^{\theta T} h+6 E_{5} h
\end{array}\right) \\
& \frac{\partial^{2} \pi(p, T)}{\partial p^{2}}=\frac{\partial^{2} \psi(p, T)}{\partial p^{2}}-\frac{a p^{-\eta-2}(\eta+1) \eta}{6 \theta T}\left(\begin{array}{l}
2 E_{4} T^{3} h \theta+3 E_{3} T^{2} h \theta-6 C E_{5} e^{\theta T} \theta \\
+6 E_{2} h T \theta+6 C E_{2} \theta-6 E_{5} e^{\theta T} h+6 E_{5} h
\end{array}\right) \\
& \frac{\partial \pi(p, T)}{\partial T}=\frac{\partial \psi(p, T)}{\partial T}-\frac{1}{6 \theta T^{2}}\left(\begin{array}{l}
6 C E_{1} E_{4} e^{\theta T} T^{3} \theta^{2}+6 C E_{1} E_{3} e^{\theta T} T^{2} \theta^{2} \\
+6 E_{1} E_{4} e^{\theta T} T^{3} \theta h+6 C E_{1} E_{2} e^{\theta T} T \theta^{2} \\
+6 C E_{1} E_{4} e^{\theta T} T^{2} \theta+6 E_{1} E_{3} e^{\theta T} T^{2} \theta h \\
-4 E_{1} E_{4} T^{3} \theta h+6 E_{1} E_{2} e^{\theta T} T h \theta \\
-3 E_{1} E_{3} T^{2} \theta h+6 E_{1} E_{4} e^{\theta T} T^{2} h \\
-6 C E_{1} E_{2} e^{\theta T} \theta-6 E_{1} E_{4} T^{2} h \\
+6 C E_{1} E_{2} \theta-6 E_{1} E_{2} e^{\theta T} h+6 E_{1} E_{2} h \\
+6 A \theta
\end{array}\right) \\
& \frac{\partial^{2} \pi(p, T)}{\partial T^{2}}=\frac{\partial^{2} \psi(p, T)}{\partial T^{2}}+\frac{1}{3 \theta T^{3}}\left(\begin{array}{l}
-3 C E_{1} E_{4} e^{\theta T} T^{4} \theta^{3}-3 C E_{1} E_{3} e^{\theta T} T^{3} \theta^{3} \\
-3 E_{1} E_{4} e^{\theta T} T^{4} \theta^{2} h-3 C E_{1} E_{2} e^{\theta T} T^{2} \theta^{3} \\
-6 C E_{1} E_{4} e^{\theta T} T^{3} \theta^{2}-3 E_{1} E_{3} e^{\theta T} T^{3} \theta^{2} h \\
-3 E_{1} E_{2} e^{\theta T} T^{2} h \theta^{2}-6 E_{1} E_{4} T^{3} \theta h \\
+6 C E_{1} E_{2} e^{\theta T} T \theta^{2}+2 E_{1} E_{4} T^{3} h \theta \\
6 C E_{1} E_{2} e^{\theta T} T h \theta-6 C E_{1} E_{2} e^{\theta T} \theta \\
+6 C E_{1} E_{2} \theta-6 E_{1} E_{2} e^{\theta T} h+6 E_{1} E_{2} h+6 A \theta
\end{array}\right) \\
& \frac{\partial^{2} \pi(p, T)}{\partial p \partial T}=\frac{\partial^{2} \pi(p, T)}{\partial T \partial p}=\frac{\partial^{2} \psi(p, T)}{\partial T \partial p}-\frac{a p^{-\eta-1} \eta}{6 \theta T^{2}}\left(\begin{array}{l}
6 C E_{4} e^{\theta T} T^{3} \theta^{2}+6 C E_{3} e^{\theta T} T^{2} \theta^{2} \\
+6 E_{4} e^{\theta T} T^{3} h \theta+6 C E_{2} e^{\theta T} T \theta^{2} \\
+6 C E_{4} e^{\theta T} T^{2} \theta+6 E_{3} e^{\theta T} T^{2} h \theta \\
-4 E_{4} T^{3} h \theta+6 E_{2} e^{\theta T} T h \theta \\
-3 E_{3} T^{2} h \theta+6 E_{4} e^{\theta T} T^{2} h \\
-6 C E_{2} e^{\theta T} \theta-6 E_{4} T^{2} h \\
+6 C E_{2} \theta-6 E_{2} e^{\theta T} h+6 E_{2} h
\end{array}\right)
\end{aligned}
$$

Hessian matrix is $H(p, T)=\left[\begin{array}{ll}\frac{\partial^{2} \pi(p, T)}{\partial T^{2}} & \frac{\partial^{2} \pi(p, T)}{\partial p \partial T} \\ \frac{\partial^{2} \pi(p, T)}{\partial T \partial p} & \frac{\partial^{2} \pi(p, T)}{\partial p^{2}}\end{array}\right]$. 
Acknowledgements. The work is supported by the National Research Foundation of Korea (NRF) grant, funded by the Korea Government (MSIT) (NRF- 2020R1F1A1064460).

\section{REFERENCES}

[1] S. Bruckner, A. Albrecht, B. Petersen and J. Kreyenschmidt, A predictive shelf life model as a tool for the improvement of quality management in pork and poultry chains. Food Control 29 (2013) 451-460.

[2] L.E. Cárdenas-Barrón and S.S. Sana, Multi-item EOQ inventory model in a two-layer supply chain while demand varies with a promotional effort. Appl. Math. Model. 39 (2015) 6725-6737.

[3] B.R. Chowdhury, R. Chakraborty and U.R. Chaudhuri, The validity of modified Gompertz and Logistic models in predicting cell growth of Pediococcus Acidilactici H during the production of bacteriocin pediocin AcH. J. Food Eng. 80 (2007) 1171-1175.

[4] B.K. Dey, B. Sarkar, M. Sarkar and S. Pareek, An integrated inventory model involving discrete setup cost reduction, variable safety factor, selling price dependent demand, and investment. RAIRO: OR 53 (2019) 39-57.

[5] T.J. Fang, Q.K. Wei, C.W. Liao, M.J. Hung and T.H. Wang, Microbiological quality of $18^{\circ} \mathrm{C}$ ready-to-eat food products sold in Taiwan. Int. J. Food Microbiol. 80 (2003) 241-250.

[6] A.M. Gibson, N. Bratchell and T.A. Roberts, The effect of sodium chloride and temperature on rate and extent of growth of clostridium botulinum type an unpasteurized pork slurry. J. Appl. Bacteriol. 62 (1987) 479-490.

[7] J.W. Grievink, L. Josten and C. Valk, State of the art in food: The changing face of the worldwide food industry. Elsevier Business Information (2002) 663.

[8] A. Herbon, E. Levner and T.C.E. Cheng, Perishable inventory management with dynamic pricing using time-temperature indicators linked to automatic detecting devices. Int. J. Prod. Econ. 147 (2014) 605-613.

[9] M.W. Iqbal and B. Sarkar, Recycling of lifetime dependent deteriorated products through different supply chains. RAIRO: OR 53 (2019) 129-156.

[10] D.H. Jang and K.T. Lee, Quality changes of ready-to-eat ginseng chicken porridge during storage at $25^{\circ} \mathrm{C}$. Meat Sci. $92(2012)$ 469-473.

[11] J. Jemai, B.D. Chung and B. Sarkar, Environmental effect for a complex green supply-chain management to control waste: a sustainable approach. J. Clean. Prod. 277 (2020) 122919.

[12] M.A.A. Khan, A.A. Shaikh, G. Panda, I. Konstantaras and L.E. Cárdenas-Barrón, The effect of advance payment with discount facility on supply decisions of deteriorating products whose demand is both price and stock dependent. Int. Trans. Oper. Res. 27 (2020) 1343-1367.

[13] R.H. Linton, W.H. Carter, M.D. Pierson and C.R. Hackney, Use of a modified Gompertz equation to model nonlinear survival curves for Listeria Monocytogenes Scott A. J. Food Prot. 58 (1995) 946-954.

[14] A.S. Mahapatra, B. Sarkar, M.S. Mahapatra, H.N. Soni, and S.K. Mazumder, Development of a fuzzy economic order quantity model of deteriorating items with promotional effort and learning in fuzziness with a finite time horizon. Inventions 4 (2019) 36 .

[15] A. Mukherjee and G.C. Mahata, Optimal replenishment and credit policy in an inventory model for deteriorating items under two-levels of trade credit policy when demand depends on both time and credit period involving default risk. RAIRO: OR $\mathbf{5 2}$ (2018) 1175-1200.

[16] S. Mukhopadyay, R.N. Mukherjee and K.S. Chaudhuri, Joint pricing and ordering policy for a deteriorating inventory. Comput. Ind. Eng. 47 (2004) 339-349.

[17] Y. Qin, J. Wang and C. Wei, Joint pricing and inventory control for fresh produce and foods with quality and physical quantity deteriorating simultaneously. Int. J. Prod. Econ. 152 (2014) 42-48.

[18] M. Rabbani, N.P. Zia and H. Rafiei, Coordinated replenishment and marketing policies for non-instantaneous stock deterioration problems. Comput. Ind. Eng. 88 (2015) 49-62.

[19] M. Rabbani, N.P. Zia and H. Rafiei, Joint optimal inventory, dynamic pricing, and advertisement policies for non-instantaneous deteriorating items. RAIRO: OR 51 (2017) 1251-1267.

[20] B. Sarkar, B.K. Sett and G. Roy, Flexible setup cost and deterioration of products in a supply chain model. Int. J. Appl. Comput. Math. 2 (2016) 25-40.

[21] B. Sarkar, B.K. Dey, M. Sarkar, S. Hur, B. Mandal and V. Dhaka, Optimal replenishment decision for retailers with variable demand for deteriorating products under a trade-credit policy. RAIRO Oper. Res. 54 (2020) 1685-1701.

[22] B. Sarkar, M. Sarkar, B. Ganguly and L.E. Cárdenas-Barrón, Combined effects of carbon emission and production quality improvement for fixed lifetime products in a sustainable supply chain management. Int. J. Prod. Econ. 231 (2021) 107867.

[23] N. Saxena, B. Sarkar and S.R. Singh, Selection of remanufacturing/production cycles with an alternative market: a perspective on waste management. J. Clean. Prod. 245 (2020) 118935.

[24] N.H. Shah and U.B. Chaudhari, Optimal policies for three players with fixed life time and two-level trade credit for time and credit dependent demand. Adv. Ind. Eng. Manage. 4 (2015) 89-100.

[25] N.H. Shah and M.Y. Jani, Optimal ordering for deteriorating items of fixed-life with quadratic demand and two-level trade credit. In: Optimal Inventory Control and Management Techniques. IGI Global (2016) 1-16.

[26] N.H. Shah and M.Y. Jani, Economic order quantity model for non-instantaneously deteriorating items under order-sizedependent trade credit for price-sensitive quadratic demand. AMSE J. 37 (2016) 1-19.

[27] N.H. Shah, M.Y. Jani and D.B. Shah, Economic order quantity model under trade credit and customer returns for pricesensitive quadratic demand. Rev. Invest. Oper. 36 (2015) 240-248. 
[28] N.H. Shah, U.B. Chaudhari and M.Y. Jani, Optimal down-stream credit period and replenishment time for deteriorating inventory in a supply chain. J. Basic Appl. Res. Int. 14 (2015) 101-115.

[29] N.H. Shah, M.Y. Jani and U.B. Chaudhari, Impact of future price increase on ordering policies for deteriorating items under quadratic demand. Int. J. Ind. Eng. Comput. 7 (2016) 423-436.

[30] N.H. Shah, U. Chaudhari and L.E. Cárdenas-Barrón, Integrating credit and replenishment policies for deteriorating items under quadratic demand in a three echelon supply chain. Int. J. Syst. Sci. Oper. Logist. 7 (2020) 34-45.

[31] A.A. Shaikh, L.E. Cárdenas-Barrón, A.K. Bhunia and S. Tiwari, An inventory model of a three-parameter Weibull distributed deteriorating item with variable demand dependent on price and frequency of advertisement under trade credit. $R A I R O: O R$ 53 (2019) 903-916.

[32] A.A. Shaikh, L.E. Cárdenas-Barrón and S. Tiwari, A two-warehouse inventory model for non-instantaneous deteriorating items with interval valued inventory costs and stock dependent demand under inflationary conditions. Neural Comput. App. 31 (2019) 1931-1948.

[33] E. Stavropoulou and E. Bezirtzoglou, Predictive modeling of microbial behavior in food. Foods 8 (2019) 654.

[34] A. Taleizadeh and M. Nematollahi, An inventory control problem for deteriorating items with back-ordering and financial considerations. Appl. Math. Model. 38 (2014) 93-109.

[35] J. Wang, J. Chen, Y. Hu, H. Hu, G. Liu and R. Yan, Application of a predictive growth model of pseudomonas spp. for estimating shelf life of fresh Agaricus bisporus. J. Food Prot. 80 (2017) 1676-1681.

[36] R.C. Whiting and R.L. Buchanan, A classification of models in predictive microbiology. Food Microbiol. 10 (1993) $175-177$.

[37] M.F. Yang and W.C. Tseng, Deteriorating inventory model for chilled food. Math. Prob. Eng. 2015 (2015) 816876.

[38] J. Zhang, G. Liu, Q. Zhang and Z. Bai, Coordinating a supply chain for deteriorating items with a revenue sharing and cooperative investment contract. Omega 56 (2015) 37-49.

[39] L.C. Iao, H.I. Hsiao and M.F. Yang, Temperature monitoring for quality prediction and inventory control in cold chain: A case of $18^{\circ} \mathrm{C}$ ready-to-eat food in Taiwan. 7 th International European Forum (Igls-Forum) on System Dynamics and Innovation in Food Networks, Innsbruck, Austria. (2013) 593-600.

\section{Subscribe to Open (S20) A fair and sustainable open access model}

This journal is currently published in open access under a Subscribe-to-Open model (S2O). S2O is a transformative model that aims to move subscription journals to open access. Open access is the free, immediate, online availability of research articles combined with the rights to use these articles fully in the digital environment. We are thankful to our subscribers and sponsors for making it possible to publish this journal in open access, free of charge for authors.

\section{Please help to maintain this journal in open access!}

Check that your library subscribes to the journal, or make a personal donation to the $\mathrm{S} 2 \mathrm{O}$ programme, by contacting subscribers@edpsciences.org

More information, including a list of sponsors and a financial transparency report, available at: https://www. edpsciences.org/en/maths-s2o-programme 